\title{
Instability of the lumbar spine due to disc degeneration. A finite element simulation
}

\author{
Elena Ibarz ${ }^{1,2}$, Yolanda Más ${ }^{1,2}$, Jesús Mateo ${ }^{3,4,5}$, Antonio Lobo-Escolar ${ }^{3,4,5}$, Antonio Herrera ${ }^{3,4,5}$, \\ Luis Gracia ${ }^{1,2}$
}

${ }^{1}$ Department of Mechanical Engineering, University of Zaragoza, Zaragoza, Spain

${ }^{2}$ Aragón Institute for Engineering Research (I3A), Zaragoza, Spain

${ }^{3}$ Department of Surgery, University of Zaragoza, Zaragoza, Spain

${ }^{4}$ Department of Orthopaedic Surgery and Traumatology, Miguel Servet University Hospital, Zaragoza, Spain

${ }^{5}$ Aragón Health Sciences Institute, Zaragoza, Spain

Email: lugravi@unizar.es

Received 17 January 2013; revised 4 March 2013; accepted 7 April 2013

Copyright (C) 2013 Elena Ibarz et al. This is an open access article distributed under the Creative Commons Attribution License, which permits unrestricted use, distribution, and reproduction in any medium, provided the original work is properly cited.

\begin{abstract}
Low back pain, which most common cause is degenerative disc disease, currently represents a serious problem due to its socio-economic repercussions. Different factors are involved in the degenerative process, being the most common: the loads on the spine, repeated flexion movements and individual genetic characteristics. Nowadays, there is no agreement on whether instability is the main cause of low back pain, or only one reason among many, and on whether increased spinal mobility, associated with instability, occurs either locally or at the lumbar spine as a whole. In this work, the simulation of disc degeneration is based on a finite element model of lumbar spine. A parametric study based on mechanical properties was established, for each lumbar spine movement, by evaluating the disc degeneration in $10 \%$ steps, from healthy disc to maximum degeneration. The results show as general trend a progressive mobility increase as the disc degeneration level raises. As main conclusion, disc degeneration causes increased mobility at all vertebral levels, with moderate values for incipient degeneration and much higher values for advanced degeneration, affecting more severely to the levels closest to degenerated disk. The great mobility increase detected at $L 5$ could explain the instability detected as a clinical symptom.
\end{abstract}

Keywords: Lumbar Spine; Finite Elements; Biomechanics; Kinematics; Mobility; Disc Degeneration

\section{INTRODUCTION}

Degenerative disc disease is the most common cause of low back pain [1]. This problem may affect both sexes although it is more prevalent in men. Its significant incidence, morbidity and economic consequences, being the most common cause of disability in working-age people, have turned degenerative disc disease into a prominent topic of study. Research in this field is aimed at analyzing its epidemiology, etiology, biomechanical impact, structural and biochemical alterations of the intervertebral disc and the adjacent bony and ligamentous structures, neurological implications and possibilities of treatment [2].

The main factors, among others, involved in the degenerative process of intervertebral disc are: the loads on the spine [3] which can also activate enzymatic processes influencing the degeneration [4], repeated flexion movements [5], and individual genetic characteristics [6, 7].

Signs of degenerative disc disease are frequently seen on MRI, but many of these patients are asymptomatic [8]. Moreover, patients' symptoms are variable and inaccurate diagnoses are often made [9]. The most common symptom is pain, of which causes are diverse and act in a combined form: instability associated with disc degenerative process, cartilage abnormalities and osteoarthritis of the facet joints, nerve compression by disc material, ligaments or bone, and the presence of biochemical mediators of inflammation and pain [2].

The pathogenesis of disc degeneration was first described by Kikardy-Willis in the 1980s [10,11]. He stated three phases in the evolution of the process: 1) temporary dysfunction, 2) unstable phase, and 3) stabilization. In the second phase, the degenerative process of the disc involves disruption of the collagen fibers, decrease in proteoglycan content, loss of water content and a clear re- 
duction in elasticity. Thus, the fibrous annulus structure becomes altered and tears may appear [12]. These changes lead to decreased disc height, which together with the changes that occur in all structures of the tripod joint, produce instability. Instability progression results in degenerative spondylolisthesis with anterior displacement of one vertebra over another. Instability can also cause changes in the mobility of the spine, which becomes irregular, excessive or restricted [2].

There is no agreement on whether instability is the main cause of back pain. Likewise, instability as a cause of increased range of motion of the lumbar spine is controversial. Some authors found an increased range of motion [13], particularly in rotational movements, flexion-extension movements, and combined lateral bending and rotation movements [14]. In [15] is described an increased range of motion especially in axial rotation. In [16] an increase of vertebral displacement and mobility in flexion and extension is found in a group of patients with disc degeneration. However, other authors [17] have found a decreased range of motion in degenerated disc spaces. In [18] no increase in mobility is detected during early stages of degeneration. In Kulig [19] a MRI study is presented comparing low back pain patients with asymptomatic individuals. An equivalent fixed global movement is defined by an imposed position. So, the mobility of each lumbar segment is analyzed. The results show greater mobility in all segments in patients suffering from low back pain (disc degeneration symptom). Most of these studies have been made using cadaveric specimens of lumbar spine.

About finite elements simulation, in Natarajan [20] an application for analysis of disc degeneration in varying degrees is presented. Variations in disc height are measured after applying cyclic loads. The conclusion is somewhat contradictory: mobility is greater in healthy disks than in degenerated ones. Iatridis [21] uses the concept of mechanical damage applied to composite materials in order to identify potential failure mechanisms in the annulus, but it doesn't provide results on spinal mobility. In Natarajan [22] an identical model to that of [20] is described, with the same results, adding only a failure criterion to assess the percentage of disc volume affected by degeneration. In [23] a discussion is set out about the accuracy of in vitro and in vivo models for the study of disc degeneration. Rohlmann [24] makes an analysis of the four basic movements, for different degrees of disc degeneration. An increased range of motion is shown in moderate disc degeneration cases, being this effect more pronounced during extension movements. In Schmidt [25] a finite element study of disc degeneration at L4-L5 functional unit is presented, but results of mobility are not provided (disc height is previously fixed in each model, depending on the severity of degeneration). In little
[26] a finite element study of disc degeneration is developed, without providing mobility outcomes. In Ruberté [27] another finite element study of disc degeneration at L4-L5 functional unit is presented. The impact of disc degeneration on the mobility is measured, both in this segment and the adjacent ones, detecting a significantly increased mobility in all planes.

In biomechanical terms, disc degeneration causes a loss of height of the intervertebral disc, which entails a loss of vertebral ligament tension, mainly in the anterior and posterior longitudinal ones. Degenerative process causes pain and patients self-restrict their mobility. Normally, physical examination shows a variable range of motion throughout the disease progression because mobility depends on pain severity, which is also variable. Certainly, degenerative disc process causes instability in the affected functional unit, and the vertebral body moves forward as the process progresses.

Mechanically, in a simulation model we expect to find an increased mobility in the intervertebral space as a result of the loss of disc height and ligament tension. In this paper, based on a model of a healthy lumbar spine, properly calibrated, we simulate the effects of disc degeneration. We chose the L5-S1 disc because it is the most frequently affected by degenerative disease. To this end, a modification is made in the stiffness of all the elements of the disc: the nucleus pulposus, and matrix and fibers of the annulus fibrosus. Movements of flexion, extension, lateral flexion and rotation are analyzed for different degrees of disc degeneration.

\section{MATERIAL AND METHODS}

The simulation of disc degeneration is based on a finite element model of a healthy lumbar spine. The model consists of five lumbar vertebrae (L1, L2, L3, L4 and L5), five intervertebral discs (L1-L2, L2-L3, L3-L4, L4-L5 and L5-S1) and the various lumbar ligaments (anterior longitudinal ligament, posterior longitudinal ligament, supraspinous ligament, interspinous ligament, intertransverse ligament, yellow ligament and iliolumbar ligament).

The first step in obtaining the finite element model is to generate the geometry of each of the component parts. Each of the components of an anatomical model of the lumbar spine (trademark Somso QS-15) are scanned (by means of a PICZA Roland laser scanner) separately (five vertebrae and five discs) to obtain the outer surface of each component. Subsequently, by means of measurements on the scanned surfaces, an ideal averaged geometry is generated from each of the parts. Then, they are positioned to form the lumbar spine model. In this case, the sacrum geometry is simplified since it serves only as a reference where support conditions will be applied. 
The above process provides only the external geometry of each of the parts. The internal geometry of the vertebrae is taken from CT scans of healthy individuals, which are scaled in each of the vertebrae until a matching size with the previously scanned geometry is reached. From these CT images, the differentiation between cortical and cancellous bone is assessed in each vertebra.

As in the vertebrae, the outer surface geometry of the intervertebral disc is acquired. Anatomically, intervertebral disc consists of two clearly differentiated parts: the central part, called "nucleus pulposus", is a transparent gelatinous substance that contains $88 \%$ water; and the peripheral part, known as annulus fibrosus, which is formed by a succession of concentric fibrous layers of which obliqueness is crossed when passing from one layer to the next. These fibers are vertical in the periphery and become more skewed as they approach the center, where are substantially horizontal in contact with the core [28].

In the model, the nucleus pulposus is generated by differentiating the nucleus volume and the annulus volume in the geometric model, based on anthropometric data obtained from specialized anatomy textbooks [28, 29]. In contrast, the different fibrous layers of intervertebral discs are included directly in the finite element model by its geometry compliant elements. Ligaments are also included in the geometric model on the basis of bibliographic data of average anatomical measurements [28].

Figure 1 shows a longitudinal section of the final geometric model.

Each of the component parts of the final geometric model is meshed independently. An automatic meshing process is used in vertebrae, and a manual meshing is applied to intervertebral discs (nucleus pulposus, fibrous annulus and fibers embedded in it) and the various ligaments. The complete model (Figure 2) consists of
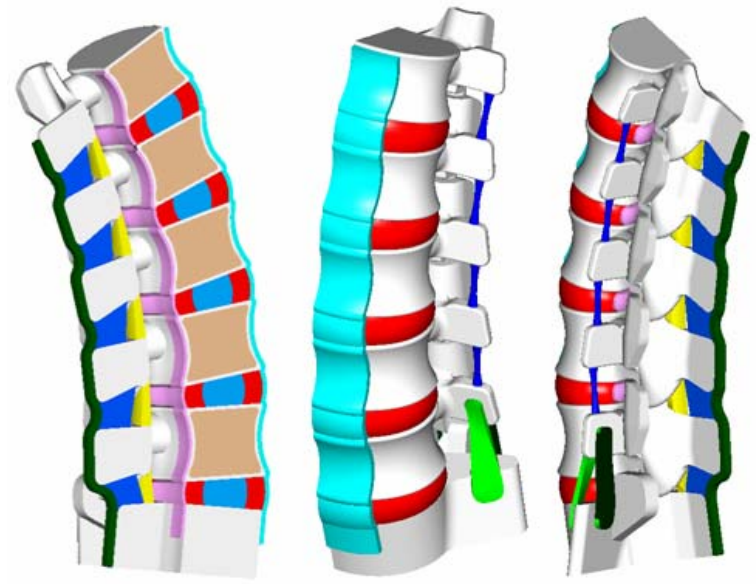

Figure 1. Longitudinal section of the geometric model for the lumbar spine. Vertebrae in white and soft tissues in several colours.
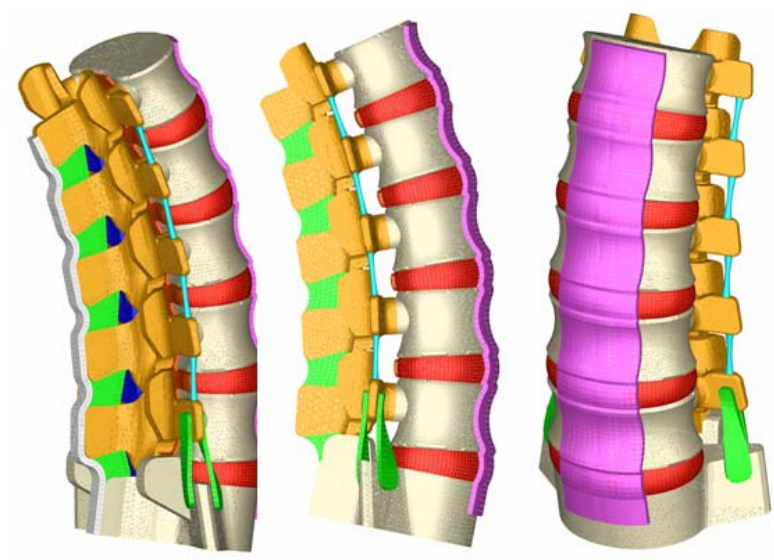

Figure 2. FE model of the whole lumbar spine. Vertebral bodies in white and apophyses and soft tissues in several colours.

387,000 elements and 176,217 nodes (528,651 degrees of freedom). Vertebrae have been modeled with tetrahedral elements (296,398 elements), the different ligaments and intervertebral discs were modeled with hexahedral elements $(81,842$ elements), the fibers embedded in the fibrous annulus have been modeled with truss type elements (7764 elements), and the 996 remaining elements correspond to wedge type elements for geometric adaptation in different areas of the model. All elements are of linear approximation, except truss elements which are of quadratic approximation. The final number of elements in the whole model was obtained after a sensitivity analysis. To this respect a mesh refinement was performed in order to achieve a convergence towards a minimum of the potential energy, both for the whole model and for each of its components, with a tolerance of $1 \%$ between consecutive meshes. Figure 3 shows a detail of the finite element model of L2-L3 vertebral disc, and Figure 4 shows a detail of the successive layers of fibers embedded in the fibrous annulus.

In order to simulate the connection between the different elements of the model, several groups of boundary conditions were considered: contact conditions between apophyses, join conditions in the various insertions of ligaments, and join conditions between vertebrae and intervertebral discs. In the latter case, the option Abaqus TIE was used [30]. Immobilization of the base of the sacrum is imposed as a support condition (Figure 5). We analyze four characteristic movements of the lumbar spine: flexion, extension, lateral flexion and rotation. Since we intend to verify mobility trends, but not quantitative values, those movements are achieved by a 20 N.m standardized moment which is applied on a node located in the center of the upper face of the L1 vertebra. This moment simulates, in a simplified way, the action of all lumbar spine muscles.

The properties attributed to the component materials 


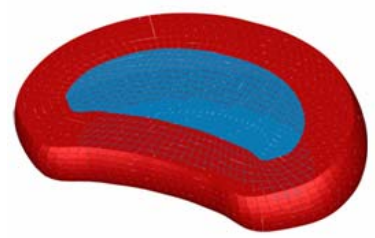

(a)

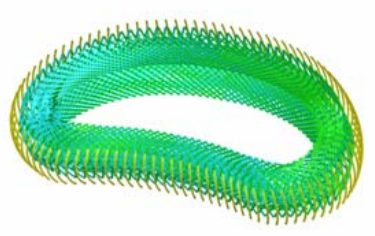

(b)
Figure 3. FE model: (a) Disc L2-L3 (in blue nucleus pulposus; in red annulus fibrosus); (b) Detail of the embedded fibers inside annulus fibrosus.

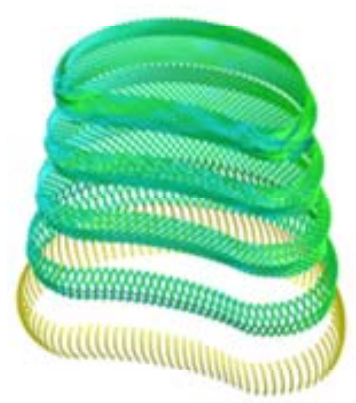

(a)

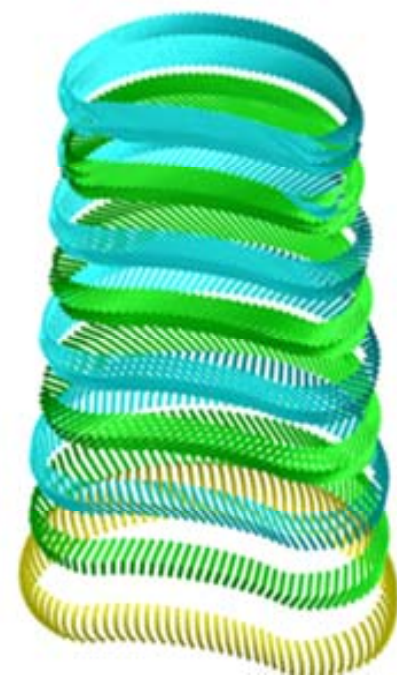

(b)
Figure 4. FE model of the fiber layers embedded in the disc L2-L3. (a) Deployment of layers; (b) Detail of the crossed orientation.

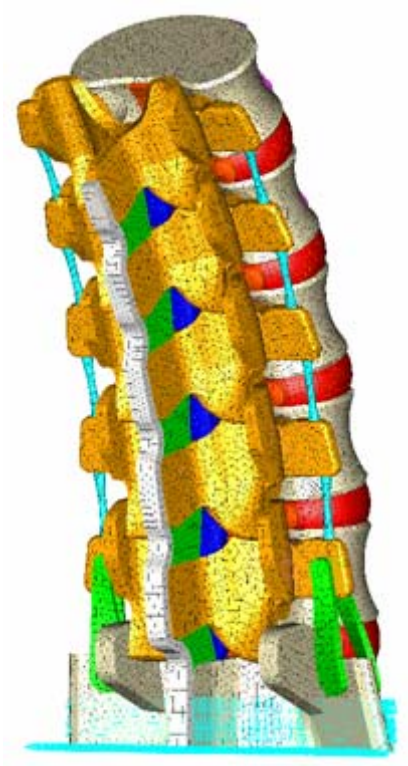

Figure 5. Boundary conditions in the FE model: immobilization at the base of the sacrum. of the healthy lumbar spine model are shown in Table 1. Two zones have been differentiated in vertebrae according to their stiffness: the vertebral body, more stiffness, and the posterior arch, less stiffness. In intervertebral discs, the nucleus pulposus is defined as an incompressible material, while a material is assigned to each of the annulus layers of fibers according to its stiffness, which is increasing from outside to inside of the disc. Ligaments, which exhibit a hypoelastic behavior, are modeled in a simplified way by assuming a bilinear behavior.

The mechanical properties of a degenerated disc, shown in Table 2, correspond to mean values from different authors $[20,22,25,27]$. To simulate L5-S1 disc degeneration, a parametric study based on mechanical

Table 1. Mechanical properties of materials.

\begin{tabular}{|c|c|c|c|c|}
\hline Material & $\begin{array}{c}\text { Young } \\
\text { modulus } \\
(\mathrm{MPa})\end{array}$ & $\begin{array}{l}\text { Poisson } \\
\text { coefficient }\end{array}$ & $\begin{array}{l}\text { Element } \\
\text { type }\end{array}$ & $\begin{array}{c}\text { Number of } \\
\text { elements }\end{array}$ \\
\hline Cortical bone & 12,000 & 0.3 & Tetrahedron & 134,504 \\
\hline Posterior vertebra & 3000 & 0.3 & Tetrahedron & 86,700 \\
\hline $\begin{array}{l}\text { Cancellous bone } \\
\text { (inside vertebrae) }\end{array}$ & 100 & 0.2 & Tetrahedron & 75,194 \\
\hline Annulus fibrosus & 4.2 & 0.45 & Hexahedron & 23,040 \\
\hline Nucleus pulposus $^{\mathrm{a}}$ & \multicolumn{2}{|c|}{$\begin{array}{c}\text { Incompressible } \\
\text { material }\end{array}$} & $\begin{array}{l}\text { Hexahedron } \\
\text { Wedge }\end{array}$ & $\begin{array}{c}19,328 \\
544\end{array}$ \\
\hline Annulus fiber layers 1 & 360 & 0.3 & Truss $^{\mathrm{b}}$ & 3840 \\
\hline Annulus fiber layers 2 & 408 & 0.3 & Truss $^{b}$ & 960 \\
\hline Annulus fiber layers 3 & 455 & 0.3 & Truss $^{b}$ & 960 \\
\hline Annulus fiber layers 4 & 503 & 0.3 & Truss $^{b}$ & 960 \\
\hline Annulus fiber layers 5 & 550 & 0.3 & Truss $^{b}$ & 1044 \\
\hline Ligament & $\begin{array}{c}\text { Young } \\
\text { modulus } \\
(\mathrm{MPa})\end{array}$ & $\begin{array}{l}\text { Transition } \\
\text { strain (\%) }\end{array}$ & $\begin{array}{l}\text { Element } \\
\text { type }\end{array}$ & $\begin{array}{l}\text { Number of } \\
\text { elements }\end{array}$ \\
\hline $\begin{array}{c}\text { Anterior longitudinal } \\
\text { ligament }\end{array}$ & $\begin{array}{c}7.8 \\
20.0\end{array}$ & 12.0 & Hexahedron & 3488 \\
\hline $\begin{array}{c}\text { Posterior } \\
\text { longitudinal ligament }\end{array}$ & $\begin{array}{l}10.0 \\
50.0\end{array}$ & 11.0 & $\begin{array}{l}\text { Hexahedron } \\
\text { wedge }\end{array}$ & $\begin{array}{c}1748 \\
320\end{array}$ \\
\hline Ligamentum flavum & $\begin{array}{l}15.0 \\
19.0\end{array}$ & 6.2 & $\begin{array}{l}\text { Hexahedron } \\
\text { wedge }\end{array}$ & $\begin{array}{c}1330 \\
92\end{array}$ \\
\hline $\begin{array}{c}\text { Intertransverse } \\
\text { ligament }\end{array}$ & $\begin{array}{l}10.0 \\
59.0\end{array}$ & 18.0 & Hexahedron & 30,208 \\
\hline $\begin{array}{l}\text { Interspinous } \\
\text { ligament }\end{array}$ & $\begin{array}{c}8.0 \\
15.0\end{array}$ & 20.0 & $\begin{array}{l}\text { Hexahedron } \\
\text { wedge }\end{array}$ & $\begin{array}{c}1100 \\
8\end{array}$ \\
\hline $\begin{array}{l}\text { Supraspinous } \\
\text { ligament }\end{array}$ & $\begin{array}{l}10.0 \\
12.0\end{array}$ & 14.0 & Hexahedron & 816 \\
\hline Iliolumbar ligament & $\begin{array}{c}7.8 \\
20.0\end{array}$ & 12.0 & $\begin{array}{l}\text { Hexahedron } \\
\text { wedge }\end{array}$ & $\begin{array}{c}784 \\
32\end{array}$ \\
\hline
\end{tabular}

$\overline{{ }^{\mathrm{a}} \mathrm{C}_{01}=0.0343 \mathrm{MPa} ; \mathrm{C}_{10}=0.1369 \mathrm{MPa} \text {. An elastic analysis with young }}$ modulus of $1.0 \mathrm{MPa}$ and Poisson ratio of 0.49 was carried out with similar results and a volume change less than $0.6 \%$. ${ }^{\mathrm{b}}$ Only tension. 
Table 2. Mechanical properties of degenerated disc.

\begin{tabular}{ccccc}
\hline & \multicolumn{2}{c}{ Healthy disc } & \multicolumn{3}{c}{$\begin{array}{c}\text { Maximum } \\
\text { degeneration }\end{array}$} \\
\cline { 2 - 5 } & $\mathrm{E}(\mathrm{MPa})$ & $v$ & $\mathrm{E}(\mathrm{MPa})$ & $v$ \\
\hline $\begin{array}{c}\text { Nucleus } \\
\text { pulposus } \\
\begin{array}{c}\text { Annulus } \\
\text { fibrosus }\end{array}\end{array}$ & $1.00^{\mathrm{a}}$ & $0.49^{\mathrm{a}}$ & 1.30 & 0.40 \\
$\begin{array}{c}\text { Annulus fiber } \\
\text { layer 1 }\end{array}$ & 360.00 & 0.45 & 6.00 & 0.35 \\
$\begin{array}{c}\text { Annulus fiber } \\
\text { layer 2 }\end{array}$ & 408.00 & 0.30 & 36.00 & 0.30 \\
$\begin{array}{c}\text { Annulus fiber } \\
\text { layer 3 }\end{array}$ & 455.00 & 0.30 & 40.80 & 0.30 \\
$\begin{array}{c}\text { Annulus fiber } \\
\text { layer 4 }\end{array}$ & 503.00 & 0.30 & 50.30 & 0.30 \\
$\begin{array}{c}\text { Annulus fiber } \\
\text { layer 5 }\end{array}$ & 550.00 & 0.30 & 55.00 & 0.30 \\
\hline
\end{tabular}

${ }^{a}$ For interpolation purposes only.

properties was established by evaluating the disc degeneration in $10 \%$ steps from healthy disc to maximum disc degeneration. An analysis is performed for each movement and each degree of degeneration. This study is not focused on local degenerated disc but on the global behavior of the lumbar spine, analyzing the influence of disc degeneration on spine mobility.

Moreover, a simulation of the maximum simultaneous degeneration of L4-L5 and L5-S1 disks is performed as well.

\section{RESULTS}

In flexion movements, there was an increase in both the displacement and rotations at all vertebral levels (Figures 6(a) and (b), respectively). At low degeneration levels, there is a moderate increase in mobility, which is becoming greater with worsening of degeneration. At degeneration levels above $50 \%$ mobility increases faster, as demonstrate the continuous steepening of the different curves. Increased mobility ranges from $6.8 \%$ in the L1 vertebra to $24.1 \%$ in the L5 vertebra. As disc degeneration progresses, mobility increases at all vertebral levels, what is shown in Figure 7. The relative mobility between $90 \%$ degeneration and $50 \%$ degeneration is much greater than the relative mobility between the latter and a healthy disc. If adjacent disc (L4-L5) is also affected by the degenerative process, mobility increase is even greater.

Extension movements also cause an increase in both the displacement and rotations at all vertebral levels (Figures 8(a) and (b), respectively). The general trend is the same as in flexion movement although, in this case, mobility increments grow faster for advanced degrees of degeneration. Increased mobility ranges from $12.9 \%$ in

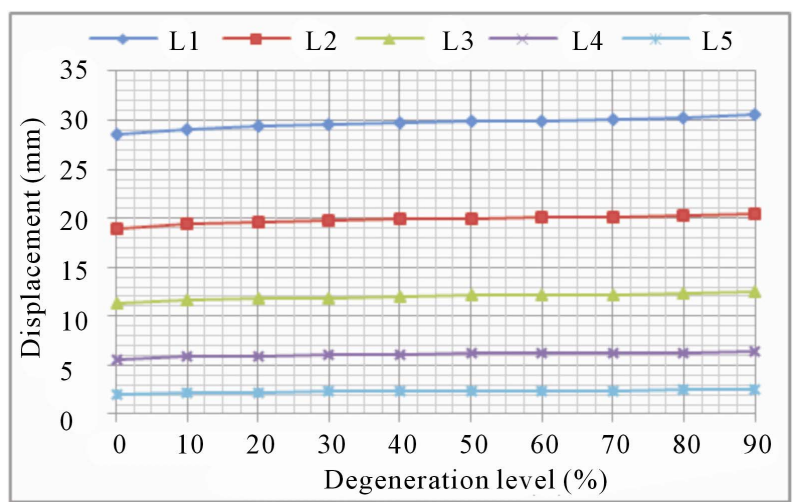

(a)

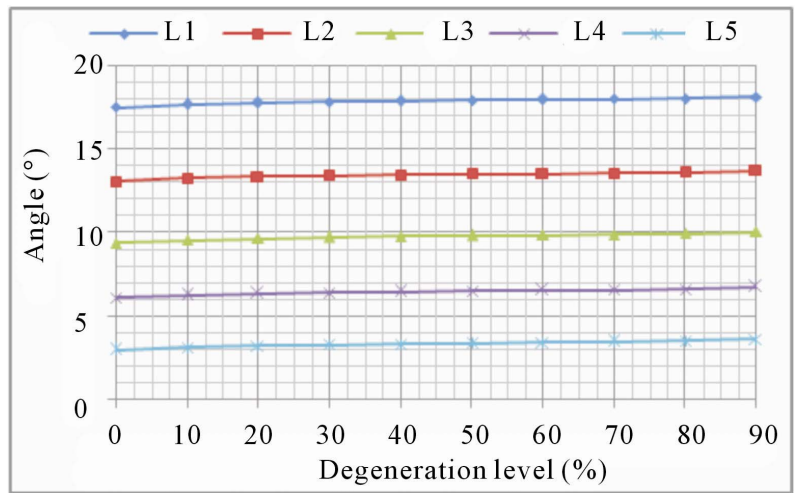

(b)

Figure 6. Flexion movement: (a) Forward displacement increase at every vertebral unit depending on the degeneration level; (b) Angle increase at every vertebral unit depending on the degeneration level.

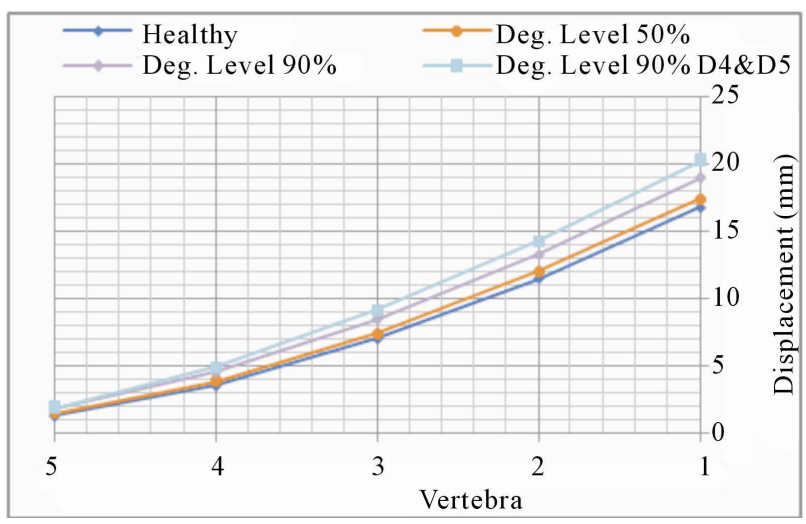

Figure 7. Flexion movement. Displacement evolution at every vertebral unit depending on the degeneration level.

the L1 vertebra up to $44.0 \%$ in the L5 vertebra.

In lateral bending the overall trend is the same as in the previous movements. Again, greater mobility increases are detected in the case of advanced degrees of degeneration (Figures 9(a) and (b), respectively). Increase in mobility ranges from $16.5 \%$ in the L1 vertebra up to $62.2 \%$ in the L5 vertebra.

Finally, rotational movements reproduce the same 


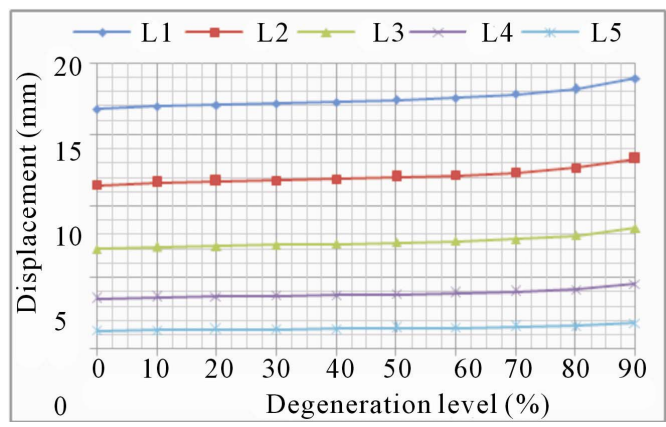

(a)

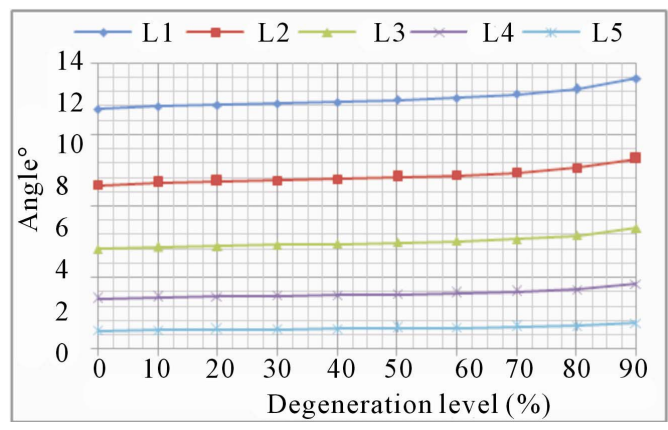

(b)

Figure 8. Extension movement: (a) Backward displacement increase at every vertebral unit depending on the degeneration level; (b) Angle increase at every vertebral unit depending on the degeneration level.

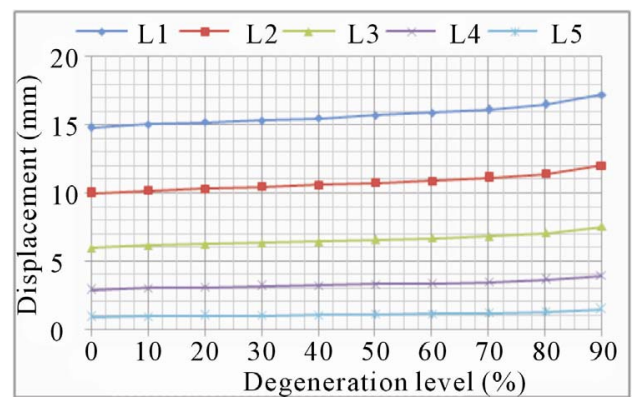

(a)

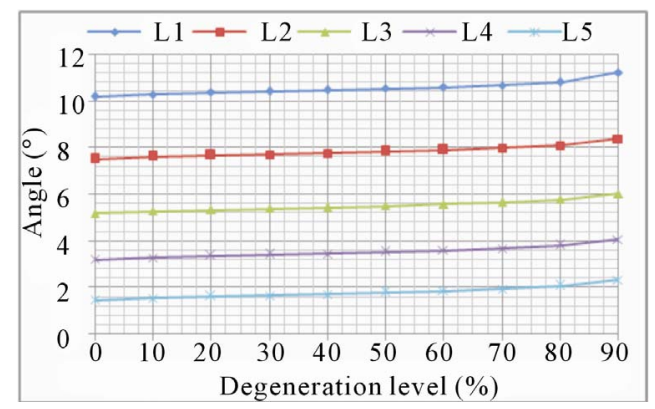

(b)

Figure 9. Lateral bending movement: (a) Lateral displacement increase at every vertebral unit depending on the degeneration level; (b) Angle increase at every vertebral unit depending on the degeneration level. trend common to all movements: the higher the degree of degeneration, the greater the mobility increase (Figures 10(a) and (b), respectively). Increased mobility ranges from $11.5 \%$ in the L1 vertebra up to $61.2 \%$ in the L5 vertebra.

Figures 11(a) and (b) show comparative results for each movement at L1 vertebral level, which is suffering the greatest absolute movement in all cases. The common trend above-described in all movements is clearly shown up, mobility increases progressively as does the degree of disc degeneration, and a sharp increase in mobility is seen with high degrees of disc degeneration (50\% and upwards).

Figure 12 shows a comparative chart of increased mobility in each vertebral unit for each of the analyzed movements, corresponding to the maximum degree of disc degeneration. Clinical instability associated to disc degeneration can be explained, from a mechanical point of view, by the great mobility increase detected at L5, in any of the analyzed movements.

\section{DISCUSSION}

Nowadays, there is no agreement on whether instability is the main cause of low back pain, or only one reason

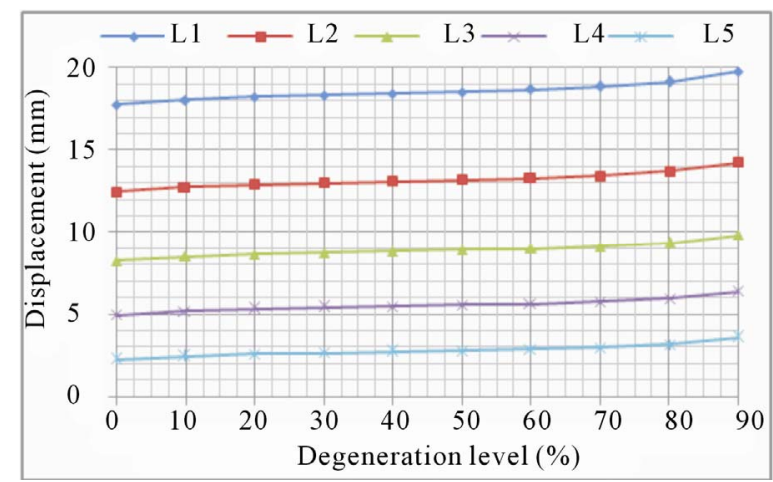

(a)

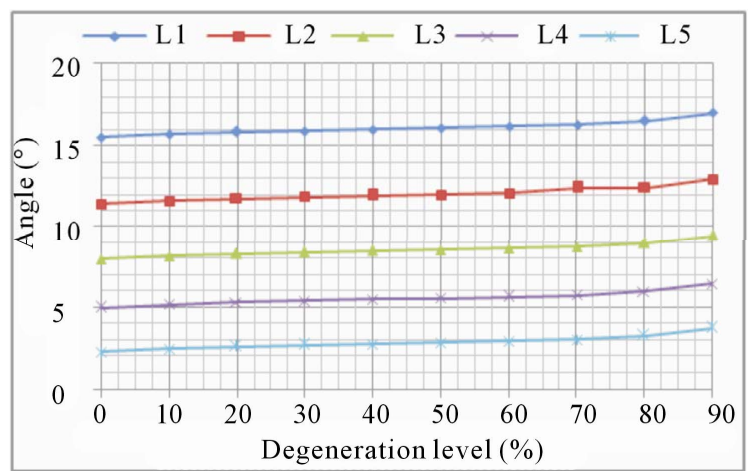

(b)

Figure 10. Axial rotation movement: (a) Rotation displacement increase at every vertebral unit depending on the degeneration level; (b) Angle increase at every vertebral unit depending on the degeneration level. 


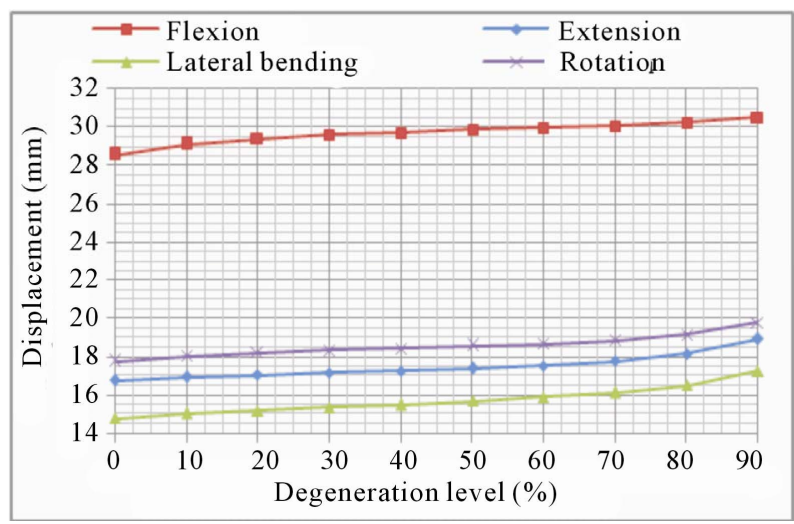

(a)

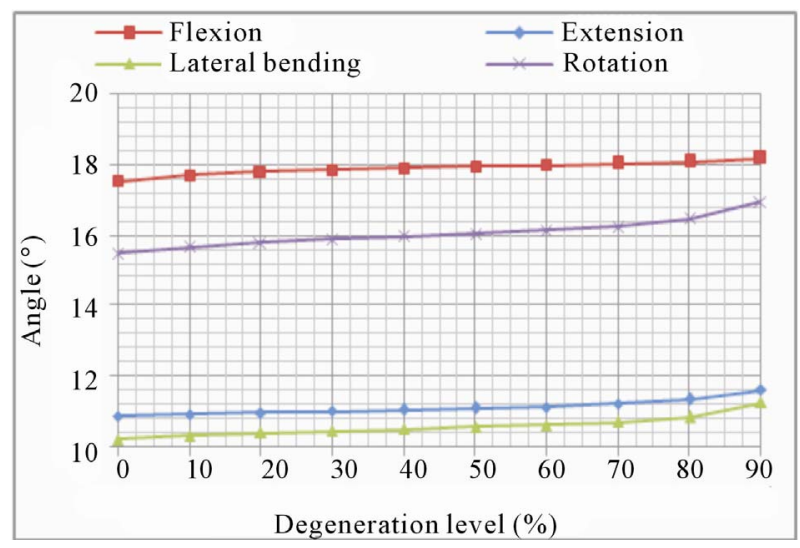

(b)

Figure 11. Movement at L1 vertebra: (a) Displacement evolution at every vertebral unit for each movement depending on the degeneration level; (b) Angle evolution at every vertebral unit for each movement depending on the degeneration level.

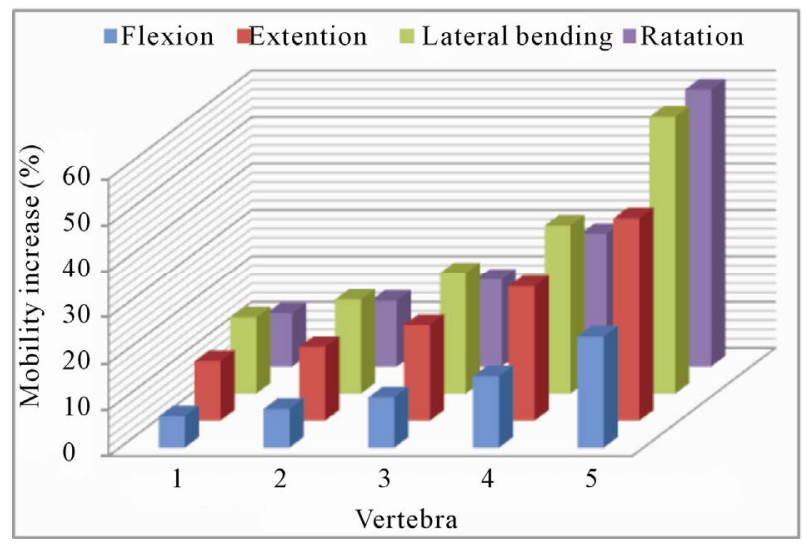

Figure 12. Increment in the mobility (\%) at every vertebral unit for the maximum disc degeneration.

among many. Likewise, there is no agreement on whether increased spinal mobility, associated with instability, occurs either locally, at vertebral units adjacent to degenerated discs, or at the lumbar spine as a whole $[14,17]$. On the other hand, most of the published studies have been conducted on cadaveric specimens. In vitro me- chanical properties of the lumbar spine components significantly differ from in vivo properties [23].

Finite elements simulation has not yet been able to tip the balance in any direction, because of the disparity of models and approaches to the problem, which have led to conflicting results $[20,24]$.

In this paper, we have proposed a parametric study for different degrees of disc degeneration at L5-S1 level, in the four basic movements of the lumbar spine (flexion, extension, lateral flexion and rotation). We have focused on the measurement of mobility changes which occur in the different vertebral units as a result of biomechanical changes (stiffness alterations) caused by disc degeneration. It is not intended in any way to relate the increased mobility with low back pain occurrence.

Regardless of quantitative mobility values, our results do show clear trends according to the simulated degree of disc degeneration. Thus, it is detected an increasing mobility trend in all movements and for all degrees of disc degeneration, both in displacements and rotations, which is in line with the results of [14,24].

We have also observed a progressive increase in mobility as disc degeneration worsened, with moderate growth at low degrees of degeneration and a much stronger growth at high degeneration degrees. That is in line with the majority of published studies, as well as clinical evidence [31-37].

An individualized analysis of each movement shows that the largest increases are detected in axial rotation mobility, in agree with $[13,15]$. Increased mobility is also more pronounced in extension, which is in agreement with $[16,24]$. Finally, a strong increase in mobility in the lateral bending movement was detected, again much more pronounced for high degrees of degeneration.

In short, as an overall conclusion of this study, disc degeneration causes increased mobility at all vertebral levels, with moderate values for incipient degeneration and much higher values for advanced degeneration, affecting more severely to the levels closest to degenerated disk. Thus, in the L5 vertebra increased mobility is 3 to 5 times higher than in the L1 vertebra, depending on the analyzed movement. If disc degeneration also occurs in the next level (L4-L5), increased mobility grows even greater. The great mobility increase detected at L5 could explain the instability detected as a clinical symptom.

Further studies are needed to verify if additional action of local muscles could influence the results shown herein.

\section{ACKNOWLEDGEMENTS}

This work has been partially financed through the projects:

a) Research Project PM100/2006, Aragón Regional Government

b) Research Project 2006-0296, Foundation SECOT 
c) Research Project ICS08/0333, Foundation Mutua Madrileña.

\section{REFERENCES}

[1] Manchikanti, L., Singh, V., Datta, S., Cohen, S.P. and Hirsch, J.A. (2009) Comprehensive review of epidemiology, scope and impact of spinal pain. Pain Physician, 12, E35-E70.

[2] Modic, M.T. and Ross, J.S. (2007) Lumbar degenerative disk disease. Radiology, 245, 43-61. doi:10.1148/radiol.2451051706

[3] Griffith, L.E., Wells, R.P. and Shannon, H.S. (2008) Developing common metrics of mechanical exposures across aetiological studies of low back pain in working populations for use in meta-analysis. Occupational and Environmental Medicine, 65, 467-481. doi:10.1136/oem.2007.034801

[4] Latridis, J.C., McLean, J.J., Roughley, P.J. and Alini, M. (2006) Effects of mechanical loading on intervertebral disc metabolism in vivo. Journal of Bone Joint Surgery American, 88, 41-46. doi:10.2106/JBJS.E.01407

[5] Wong, K.C.H., Lee, R.Y.W. and Yeung, S.S. (2009) The association between back pain and trunk posture of workers in a special school for the severe handicaps. BMC $M u-$ sculoskeletal Disorders, 29, 10-43. doi:10.1186/1471-2474-10-43

[6] Battié, M.C., Videman, T. and Parent, E. (2004) Lumbar disc degeneration: Epidemiology and genetic influences. Spine, 29, 2679-2690. doi:10.1097/01.brs.0000146457.83240.eb

[7] Battié, M.C. and Videman, T. (2006) Lumbar Disc Degeneration: Epidemiology and Genetics. Journal of Bone Joint Surgery American, 88, 3-9. doi:10.2106/JBJS.E.01313

[8] Borenstein, D.G., O’Mara Jr., J.W., Boden, S.D., Lauerman, W.C., Jacobson, A., Platenberg, C., Schellinger, D. and Wiesel, S.W. (2001) The value of magnetic resonance imaging of the lumbar spine to predict low back pain in asymptomatic subjects: A 7-year follow-up study. Journal of Bone Joint Surgery American, 83-A, 13061311.

[9] Deyo, R.A. (1993) Practice variations, treatment fads, rising disability: Do we need a new clinical research paradigm? Spine, 18, 2153-2162. doi:10.1097/00007632-199311000-00002

[10] Kirkaldy-Willis, W.H., Wedge, J.H., Yong-Hing, K., Tchang, S., de Korompay, V. and Shannon, R. (1982) Instability of the lumbar spine. Clinical Orthopaedics and Related Research, 165, 110-123.

[11] Yong-Hing, K. and Kirkaldy-Willis, W.H. (1983) The pathophysiology of degenerative disease of the lumbar spine. Orthopedic Clinics of North America, 14, 491-504.

[12] Leone, A., Guglielmi, G., Cassar-Pullicino, V.N. and Bonomo, L. (2007) Lumbar intervertebral instability. A Review. Radiology, 245, 62-77. doi:10.1148/radiol.2451051359

[13] Fujiwara, A., Lim, T.H., An, H.S., Tanaka, N., Jeon, C.H., Andersson, G.B.J. and Haughton, V.M. (2000) The effect of disc degeneration and facet joint osteoarthritis on the segmental flexibility of the lumbar spine. Spine, 25, 3036-3044. doi:10.1097/00007632-200012010-00011

[14] Tanaka, N., An, H.S., Lim, T.H., Fujiwara, A., Jeon, C.H. and Haughton, V.M. (2001) The relationship between disc degeneration and flexibility of the lumbar spine. Spine, 1, 47-56. doi:10.1016/S1529-9430(01)00006-7

[15] Krismer, M., Haid, C., Behensky, H., Kapfinger, P., Landauer, F. and Rachbauer, F. (2000) Motion in lumbar functional spine units during side bending and axial rotation moments depending on the degree of degeneration. Spine, 25, 2020-2027. doi:10.1097/00007632-200008150-00004

[16] Iguchi, T., Ozaki, T., Chin, T., Tsumura, N., Kanemura, A., Kasahara, K., Kuroda, R., Doita, M. and Nishida, K. (2011) Intimate relationship between instability and degenerative signs at L4-L5 segment examined by flex-ionextension radiography. European Spine Journal, 20, 13491354. doi:10.1007/s00586-011-1793-7

[17] Mimura, M., Panjabi, M.M., Oxland, T.R., Crisco, J.J., Yamamoto, I. and Vasavada, A. (1994) Disc degeneration affects the multidirectional flexibility of the lumbar spine. Spine, 19, 1371-1380. doi:10.1097/00007632-199406000-00011

[18] Kettler, A., Rohlmann, F., Ring, C., Mack, C. and Wilke, H.J. (2011) Do early stages of lumbar interverte-bral disc degeneration really cause instability? Evaluation of an in vitro database. European Spine Journal, 20, 578-584. doi:10.1007/s00586-010-1635-Z

[19] Kulig, K., Powers, C.M., Landel, R.F., Chen, H., Fredericson, M., Guillet, M. and Butts, K. (2007) Seg-mental lumbar mobility in individuals with low back pain: In vivo assessment during manual and self-imposed motion using dynamic MRI. BMC Musculoskeletal Disorders, 8, 8. doi:10.1186/1471-2474-8-8

[20] Natarajan, R.N., Williams, J.R. and Andersson, G.B.J. (2004) Recent advances in analytical modeling of lumbar disc degeneration. Spine, 29, 2733-2741. doi:10.1097/01.brs.0000146471.59052.e6

[21] Iatridis, J.C. and Gwynn, I. (2004) Mechanisms for mechanical damage in the intervertebral disc annulus fibrosus. Journal of Biomechanics, 37, 1165-1175. doi:10.1016/j.jbiomech.2003.12.026

[22] Natarajan, R.N., Williams, J.R. and Andersson, G.B.J. (2006) Modeling changes in intervertebral disc mechanics with degeneration. Journal of Bone and Joint Surgery, 88, 36-40. doi:10.2106/JBJS.F.00002

[23] An, H.S. and Masuda, K. (2006) Relevance of in vitro and in vivo models for intervertebral disc degeneration. Journal of Bone and Joint Surgery, 88, 88-94. doi:10.2106/JBJS.E.01272

[24] Rohlmann, A., Zander, T., Schmidt, H., Wilke, H.J. and Bergmann, G. (2006) Analysis of the influence of disc degeneration on the mechanical behaviour of a lumbar motion segment using the finite element method. Journal of Biomechanics, 39, 2484-2490. doi:10.1016/j.jbiomech.2005.07.026

[25] Schmidt, H., Kettler, A., Rohlmann, A., Claes, L. and Wilke, H.J. (2007) The risk of disc prolapses with complex loading in different degrees of disc degeneration. A 
finite element analysis. Clinical Biomechanics, 22, 988998. doi:10.1016/j.clinbiomech.2007.07.008

[26] Little, J.P., Adam, C.J., Evans, J.H., Pettet, G.J. and Pearcy, M.J. (2007) Non-linear finite element analysis of annular lesions in the L4-L5 intervertebral disc. Journal of Biomechanics, 40, 2744-2751. doi:10.1016/j.jbiomech.2007.01.007

[27] Ruberté, L.M., Natarajan, R.N. and Andersson, G.B.J. (2009) Influence of single-level lumbar degenerative disc disease on the behavior of the adjacent segments. A finite element model study. Journal of Biomechanics, 42, 341348. doi:10.1016/j.jbiomech.2008.11.024

[28] Kapandji, I.A. (2008) The Physiology of the Joints. 2nd Edition, Churchill Livingstone Inc., New York.

[29] White, A.A. and Panjabi, M.M. (1990) Clinical Biomechanics of the Spine.

[30] Abaqus Program (2012) Dassault Systèmes. http://www.3ds.com/

[31] Burton, A.K., Battié, M.C., Gibbons, L., Videman, T. and Tillotson, K.M. (1996) Lumbar disc degeneration and sagittal flexibility. Journal of Spinal Disorders, 9, 418-424. doi:10.1097/00002517-199610000-00010

[32] Axelsson, P. and Karlsson, B.S. (2004) Intervertebral mobility in the progressive degenerative process. A radiostereometric analysis. European Spine Journal, 13, 567572. doi:10.1007/s00586-004-0713-5
[33] Kong, M.H., Morishita, Y., He, W., Miyazaki, M., Zhang, H., Wu, G., Hymanson, H.J. and Wang, J.C. (2009) Lumbar segmental mobility according to the grade of the disc, the facet joint, the muscle, and the ligament pathology by using kinetic magnetic resonance imaging. Spine (Phila Pa 1976), 34, 2537-2544. doi:10.1097/BRS.0b013e3181b353ea

[34] Li, W., Wang, S., Xia, Q., Passias, P., Kozanek, M., Wood, K. and Li, G. (2011) Lumbar facet joint motion in patients with degenerative disc disease at affected and adjacent levels: An in vivo biomechanical study. Spine (Phila Pa 1976), 36, E629-E637. doi:10.1097/BRS.0b013e3181faaef7

[35] Inoue, N. and Espinoza Orías, A.A. (2011) Biomechanics of intervertebral disk degeneration. Orthopedic Clinics of North America, 42, 487-499. doi:10.1016/j.ocl.2011.07.001

[36] Taher, F., Essig, D., Lebl, D.R., Hughes, A.P., Sama, A.A., Cammisa, F.P. and Girardi, F.P. (2012). Lumbar degenerative disc disease: Current and future concepts of diagnosis and management. Advances in Orthopedics, 970752. doi:10.1155/2012/970752

[37] Iguchi, T., Nishida, K., Ozaki, T., Kitagawa, A., Tsumura, N., Kakutani, K., Yurube, T. and Kuroda, R. (2012) Grade three disc degeneration is a critical stage for anterior spondylolisthesis in lumbar spine. European Spine Journal, 21, 2134-2139. doi:10.1007/s00586-012-2288-x 